\title{
Virtual Civil Society: The New Frontier of Social Capital?
}

\author{
Miki Caul Kittilson • Russell J. Dalton
}

(C) The Author(s) 2010. This article is published with open access at Springerlink.com

\begin{abstract}
Although many scholars agree that social interactions within traditional social groups build social capital, there is less consensus on the benefits of virtual interactions for political engagement. Our research examines how interpersonal social group activity and virtual activity contribute to two dimensions of social capital: citizen norms and political involvement. We rely on data collected in the 2005 Citizenship Involvement in Democracy survey conducted by the Center for Democracy and Civil Society at Georgetown University. This survey provides unique detail on participation in both social groups and virtual interactions. Our findings suggest that social group activity and virtual interactions both foster many of the same positive aspects of social capital.
\end{abstract}

Keywords Social capital · Political participation · Internet and politics

Ever since Alexis de Tocqueville stressed the importance of America's vibrant associational life, democratic theorists have examined the relationship between participation in voluntary associations and the development of norms that underlie a stable and effective democracy. Social capital is rooted in connections among individuals, which cultivate citizenship norms, tolerance and civic activity (Putnam 1993; Uslaner 1998). Putnam's (2000) seminal research advances the idea that

\footnotetext{
M. C. Kittilson $(\bowtie)$

School of Politics and Global Studies, Arizona State University, P.O. Box 873902, Tempe, AZ 85287, USA

e-mail: Miki.Kittilson@asu.edu

R. J. Dalton

Center for the Study of Democracy, University of California, Irvine, CA 92697, USA
} 
"civic virtue is most powerful when embedded in a dense network of reciprocal social relations" (19).

Several studies have described a recent decline in social group engagement in America, and with it a concomitant decline in civic norms and political participation (Putnam 2000, 2002; Cf. Stolle and Hooghe 2005; Skocpol and Fiorina 1999; Ladd 1996; Sirianni and Friedland 2001). For instance, Putnam (2000) argues that memberships in fraternal groups, religious activities, union activities, and a host of other social associations-from bowling leagues to choral societies-have declined markedly during the last quarter of the twentieth century. This has produced dire forecasts about the vitality of American society and democracy because of the presumably negative consequences of declining social capital (Macedo et al. 2005; National Conference on Citizenship 2006).

Conversely, a different set of studies suggest that while traditional membership groups may wither, the ways in which people interact are not static, but rather evolve over time, creating new forms of social engagement. Viewed through a more long-term historic lens, the halcyon days of the Elks and bowling leagues deliver only a snapshot of citizen interactions (Bender 1978). Older types of community organizations based within neighborhoods have given way to newer communityserving organizations and more fluid connections through self-help groups, often not connected with a national umbrella group, making membership tallies more difficult (Hall 1999; Ladd 1996; Wuthnow 1998).

While some traditional forms of civic association may be declining, technological innovations also may be changing the ways in which people associate with one another. In 2009, 74\% of American adults reported using the Internet (Pew 2010). Although the initial research was skeptical of the benefits of Internet-based interaction, more recent studies suggest more positive effects of virtual activity in fostering personal interactions and democratic participation (Johnson and Kaye 2003; Shah et al. 2002; Wellman et al. 2001; Scheufele and Nisbet 2002; Boulianne 2009). Early studies typically examined the simple extent of Internet usage without regard to the nature of the usage. Much of Internet usage involves collecting information, exchanging emails or other activities that offer limited social interactions. We contend that simple undifferentiated measures of Internet usage are less relevant to social capital formation than how citizens are using the Internet today (Jennings and Zeitner 2003; Ellison et al. 2007; Baumgartner and Morris 2009; Valenzuela et al. 2009). The so-called Web 2.0 offers new opportunities for social interactions through chat rooms, on-line meetups, blogs, and social networking sites. These new technologies have greatly expanded the amount of social interaction that individuals now pursue through the Internet. These developments were unanticipated by early critiques of the social capital potential of the Internet, and thus a reappraisal is necessary.

Our key research question is whether these new forms of virtual interaction can have similar positive consequences for social capital formation as traditional social group activity. We ask whether both social group and Internet-based forms of social interactions independently contribute to two dimensions of social capital: citizenship norms and political involvement. We rely on data collected in the 2005 Citizenship Involvement Democracy survey conducted by the Center for 
Democracy and Civil Society at Georgetown University. This survey provides unique detail on participation in both social groups and Internet-based interactions, coupled with a broad range of potential social capital effects.

This research has important implications for debates over the decline in social capital in America. Although participation in traditional associations may be waning, interactions on the Internet are rising rapidly. As these new virtual forms of association proliferate, it is important to consider how they might affect civic attitudes and behaviors. Evidence that points toward the critical nature of face-toface contacts in social groups for building tolerance and political activity would bolster the argument that America's social capital is in jeopardy. However, evidence demonstrating that virtual interactions also foster democratic norms and activities would support a more positive view of current trends in associational life.

\section{Social Capital and Associations}

Social capital has a long history in social science research, so we will only briefly summarize this literature here. Social capital research often maintains that organizational involvement engenders norms of shared trust, reciprocity and civic participation (for a review of this literature, see Norris 2002, pp. 138-144). For our research, we consider social capital to be rooted in social interactions among people, and we are interested in the political consequences. Putnam's (2000) research highlights the benefits of social capital for cultivating democratic norms and habits, and ultimately for effective democracy. Civil society activity should develop the norms of civic engagement, such as the belief in an active citizen role, and other such orientations. Participation in civil society groups can produce social and organizational skills that are vital for a participatory democracy-much in the tradition of Tocqueville's image of democracy in America. The development of these social norms and skills is a prime argument of the social capital theory.

Social capital may be generated through several mechanisms, and some are more conducive to the democratic process than others. Scholars of social capital often stress that face-to-face communication networks are more likely to produce positive consequences. Putnam et al. (2003) conclude that "our investigations strongly suggest that trust relationships and resilient communities generally form through local personal contact" (9). Putnam (2000, pp. 156-157) explicitly contrasts groups that engage their members in personal interactions as compared to checkbook membership that lacks such interpersonal interactions. Face-to-face communications presumably build stronger social capital effects among members through the experience of personal interaction, the reciprocity of such interactions, and the redundancy of contacts. Howard and Gilbert (2008) similarly find that the more frequently a person is involved in voluntary organizations, the greater their generalized trust and activity in politics.

In contrast, some scholars have questioned the necessity of in-person interactions as the basis for forming social capital. Hooghe and Stolle (2003), p. 11) warn that face-to-face interactions are "less distinctive in their effects on civic attitudes than is predicted by social capital theory". The nature of the group environment or the 
types of interactions or activities may be more influential than simple membership (Warren 2000; Stolle and Rochon 1998).

\section{A Virtual Civil Society}

Technological advances in the past decade have generated significant changes in communication styles among individuals. The early days of the Internet offered limited social contact, often with a unidirectional flow of information from website to Internet user. Today, a new style of Internet activity offers substantially more opportunities for interaction. Many people join social groups through the Internet as they receive e-newsletters from their groups or visit group websites, or receive and respond to postings from Twitter. In addition, cyber associations have expanded rapidly as individuals interact through online forums, chat rooms and personal pages that are separate from traditional social groups. For example, even by 2005 more than $20 \%$ of Internet users said that they participated in a chat room or in an online discussion (Pew 2010). Social networking sites provide another venue to meet others online, share information, and interact in other ways. In 2009, 47\% of Internet users frequented online social networking sites such as MySpace, LinkedIn or Facebook (Pew 2010). These interactions have the potential to create a virtual civil society.

The evolving research on Internet interaction yields mixed results on its potential role in social capital formation in terms of the norms of citizenship and political participation. Some research suggests that because virtual associations encourage the flow of information and social interactions, this may encourage the skills of good citizenship (Corrado and Firestone 1996; Johnson and Kaye 2003; Wellman et al. 2001). Virtual associations facilitate collecting and exchanging information, and allow members to make up their own minds on issues. In this way, virtual associations may develop skills in critical analysis. Because discussions over the Internet afford users more time to reflect, information and greater control over their responses than through live conversation, they may allow freer exchange of viewpoints (McKenna and Bargh 2000). Experimental evidence supports the positive role of the Internet in facilitating civic discussion, revealing that individuals in online chat room discussions are more likely to express an opinion than individuals in face-to-face discussions (Ho and McLeod 2008).

In contrast, some studies suggest a negative or limited role for the Internet in linking citizens together. For example, Nie and Erbring (2002) find that more time spent on the Internet is associated with fewer social contacts, but their findings are from 1999 and do not examine how the Internet is being used. Significantly, a series of studies by Robert Kraut and colleagues suggest dynamic effects of Internet use over time. Kraut et al. (1998) originally reported negative effects of Internet use for social involvement. However, in a follow-up study, Kraut et al. (2002) find that, over successive waves of the panel survey, those same Internet users increased the size of their local and distant social circles, gained more face-to-face interaction with friends and family, greater community activity and social trust. Kraut et al. 
(2002, p. 68) suggest that changes in the Internet itself, including new communication services, is the "most parsimonious explanation" for this shift over time.

Finally, several studies demonstrate that Internet use is associated with higher levels of political participation. Shah et al. (2002) show that "time spent on the Internet contributes to increased levels of [civic] participation, but that civic participation is not a significant predictor of time spent online" (975). Based on panel data, Jennings and Kent (2003) find that for those who adopted Internet use between 1982 and 1997, there was positive relationship with a variety of civic participation indicators. Mossberger et al. (2008) evaluate the impact of particular online activities for voter turnout-from participating in chat room discussions to exchanging emails - and find that all are linked to voting in presidential elections. Research specific to social networking among young people demonstrates that sites such as Facebook both facilitate new and maintain established face-to-face relationships and enhance political participation, civic engagement, social trust and overall life satisfaction (Ellison et al. 2007; Valenzuela et al. 2009).

Other studies are less sanguine about the positive impact of Internet use on political participation. Krueger (2002) finds that interactions on the Internet build cyberskills that lead to online participation, but not traditional forms of participation. Among young people, social networking does not increase young adults' political knowledge or participation in traditional channels of politics, but does enhance online forms of political participation (Baumgartner and Morris 2009). A meta-analysis of 38 studies revealed that the Internet has few negative consequences for political engagement, but suggests that further research is needed to assess whether the Internet plays a positive role (Boulianne 2009).

Our research builds upon these past studies while advancing beyond this research in several ways. First, instead of measuring only undifferentiated Internet usage, we explicitly examine social interactions via the Internet. Since the initial studies often compared Internet users and non-users rather than social interaction on the Internet, they may have underestimate the actual effects of virtual civil society. Although more recent studies offer a more nuanced measure of the nature and amount of Internet use (for example, Valenzuela et al. 2009; Baumgartner and Morris 2009), most of these studies are conducted among college students, and are often limited to social networking. There are large generational differences in Internet usage and especially the use of social networking (Pew 2010), and we examine these relationships among the entire US. population. In addition, it is important to go beyond social networking websites to investigate the effects of Internet interactions more generally.

Second, we compare Internet-based social interaction to social group based activity. Specifically, are virtual interactions positively related to citizenship norms and involvement, similar to the relationship for traditional face-to-face interactions? Are these distinct forms of social interaction, or are group activists also those who participate in virtual interaction? Our key contribution is to examine how traditional face-to-face interactions compare to virtual interactions. By exploring how different forms of interaction relate to political involvement, we may improve our understanding of the mechanisms that generate social capital, and how these may be changing over time. 


\section{Measuring Civil Society Activity}

One of the challenges in studying civil society is to agree on what it means, as a precursor to measuring public involvement in civil society activity. This challenge is compounded when we want to compare in-person engagement versus virtual civil society. For the former, there is considerable debate on whether membership in any social group sufficient to promote social capital (Warren 2000; Stolle and Rochon 1998). For the latter, the options are even more diverse. A substantial part of Internet activity can involve impersonal activities such as ordering from a catalogue or looking up information. However, the Internet also opens a virtual door to a vast array of potential interpersonal interactions. These range from social networking sites of various forms, to reading and contributing to online forums, to the collaborative activity in Internet communities (such as in World of Warcraft, Second Life, and other communities). Explicit political activity on the web is less common (such as discussion groups on political websites or connecting to like-minded citizens through Moveon.org). However, the civil society thesis holds that social interactions - even in non-political social groups or non-political web groups - can produce social capital. We are fortunate to have a dataset that focused on measuring civil society activity in both domains in forms that might reflect social capital formation.

The "Citizenship, Involvement and Democracy" (CID) survey of the Center for the Democracy and Civil Society at Georgetown University examined the political values and behaviors of the American public. The nationally-representative survey conducted in-person interviews with 1001 respondents between May 16 and July 19, 2005. International Communications Research (ICR) did the interviews using a clustered, area-probability sample of households and random selection of respondents. ${ }^{1}$

The measurement of in-person social activity is relatively straightforward. The CID survey asked a typical battery about membership and participation in a list of 16 social groups (plus an "other" category in which the respondent could identify another group $)^{2}$ :

Q. 39. Now I have some questions about voluntary organizations. For each of the voluntary organizations I will now mention, please use this card to tell me whether any of these things apply to you now or in the last 12 months, and, if so, which. A member of such an organizations; Participated in an activity arranged by such an organization; Donated money to such an organization; done voluntary (unpaid) work for such an organization.

\footnotetext{
1 Additional information on the survey, its sampling design and representativeness, the questionnaire, and other findings are available from the project website: www.uscidsurvey.org/.

2 The list of groups includes: sports club, cultural or hobby activities, trade union, business association, humanitarian or human rights group, environmental or animal rights group, political party, education or science group, social club or fraternal organization, community or neighborhood association, veterans association, ethnic or nationality group, self-improvement or self-help group, social services group, or other group. See the project website for the full wording of each item.
} 
Table 1 In-person and Internet based civil society activity

\begin{tabular}{llll}
\hline & $\begin{array}{l}\text { Number of interpersonal } \\
\text { social group memberships }\end{array}$ & $\begin{array}{l}\text { Number of interpersonal } \\
\text { social group participations }\end{array}$ & $\begin{array}{l}\text { Number of } \\
\text { virtual social interactions }\end{array}$ \\
\hline$>6$ & 3.4 & 2.9 & 6.2 \\
5 & 2.2 & 2.1 & 5.5 \\
4 & 4.8 & 2.9 & 5.3 \\
3 & 7.2 & 4.6 & 5.7 \\
2 & 11.9 & 6.8 & 7.2 \\
1 & 19.6 & 14.4 & 8.9 \\
None & 51.0 & 66.4 & 61.1 \\
Mean & 1.20 & .84 & 1.28 \\
$(N)$ & $(1001)$ & $(1001)$ & $(1001)$ \\
\hline
\end{tabular}

Source: CID Survey 2005

Note: Table entries are percentages in each column, with the mean and $N$ for each type of activity

Studies of social capital often measure only membership in social groups, and the CID goes the additional step of measuring actual participation in these groups to capture the social interactions central to the social capital theory.

It is important to distinguish between the different types of social groups and their potential to develop politically relevant norms and skills, but the analyses presented here focus on mapping the overall impact of social activity. Therefore, we simply counted the number of groups each respondent belonged to, and the number of groups in which they participated. The first two data columns of Table 1 display these results.

Although the survey presented respondents with a long list of possible social groups, half of Americans (51.0\%) say they are not a member of any group. A sixth of the American public belongs to three or more social groups. The second column displays the percentages who have participated in an activity of the group, which necessitates in-person interaction. The level of participants drops off significantly, with two-thirds reporting no participation.

To measure participation in virtual civil society, the CID survey focused on social interactions that occurred over the Internet as a comparison to in-person interactions in a social group. The CID asked a battery of seven questions:

Q. 7. Please tell how much, if at all, the Internet has helped you do each of the following things? How about (READ ITEM). Would you say a lot, some, only a little, or not at all?

a. Become more involved with groups and organizations you already belong to

b. Interact with people or groups who share your hobbies or interests

c. Interact with people or groups who share your religious beliefs

d. Interact with people or groups who share your political views

e. Interact with people of a different race from yours

f. Interact with people of different ages or generations

g. Interact with people from other countries 


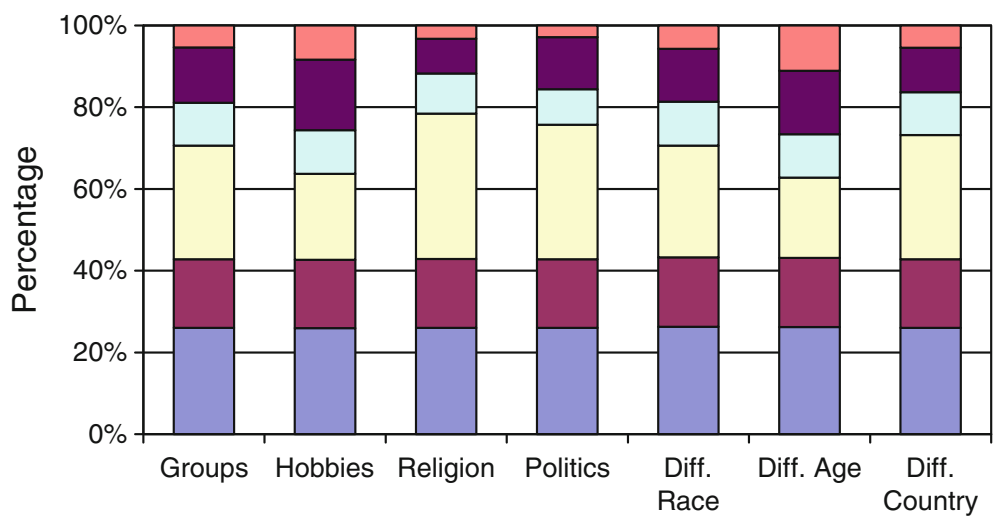

$\square$ No access $\square$ No use $\square$ Not at all $\square$ Only little $\square$ Some $\square$ A lot

Fig. 1 The distribution of Internet-based social interactions

The advantage of this battery is that it does not just measure the amount of time spent on the Internet, but focuses specifically on social interactions done over the Internet. $^{3}$ Much as with the group participation question, this includes social interactions in a variety of settings - the exact phenomenon that is central to the social capital thesis. Thus, the two measures are not necessarily equivalent in the sense that one interpersonal interaction equals one virtual interaction. Rather, the common denominator among interpersonal and virtual interaction is interactions with other people, as opposed to passive checkbook memberships or watching YouTube.

The distribution of responses across these virtual interaction options illustrates the diverse pattern of Internet activity (Fig. 1). As a baseline, nearly two-fifths of our sample report having no Internet access or never using the Internet (43\%). Still, a fifth of Americans say that the Internet helps them a lot or somewhat to become more involved in existing groups (19\%); and substantial numbers use the Internet to interact with people sharing their hobbies $(25 \%)$, their religious belief $(13 \%)$, or their political beliefs $(15 \%)$. In addition, the Internet broadens social networks beyond the immediate community and existing social networks. Web activity often starts as a color-blind and gender-blind medium, so people of different races or genders can interact without first knowing each other's identity. Thus, bridging interactions are quite common. Many respondents reported that they interacted with people of a different race (18\%), of different ages (26\%), or from other countries (16\%). Almost by definition, Internet interactions open the door to a broader social network than an individual's immediate physical network.

\footnotetext{
${ }^{3}$ We are thus skeptical of previous research that often uses measures of Internet usage as a predictor, without determining what is done on the Internet. Participating in a chat room seems more analogous to social group activity than does ordering a book from Amazon.com.
} 
The third column in Table 1 displays the distribution of virtual activity counting the number who say "a lot" or "some" participation. ${ }^{4}$ A majority report no Internet interactions at this level $(61.1 \%)$. Among those who interact, more report multiple forms of interaction; $17.0 \%$ report interacting in three or more of the listed options. The average interaction through the Internet (1.28 items) is actually higher than for membership in social groups (1.20) or participation in social groups (.84)—even though the social group list included 16 possible groups. Furthermore, two-fifths of the sample report no Internet access or no usage of the Internet; these respondents were not asked this battery of questions. Thus, if we focus only on those individuals who have access to the Internet reports of social interaction through the Internet are substantially greater (data not shown).

We believe both aspects of civil society participation-social groups and virtual interactions - can be complimentary forms of social engagement. Indeed, there is a positive relationship between in-person and virtual civil society participation (approximately $r=.20$ depending on the choice of index). Virtual civil society may thus partially represent an extension of the past patterns of social engagement to a new medium.

At the same time, virtual civil society represents a new style of social engagement that draws different people into social activity. For instance, as one might expect, membership in social groups strongly increases with age $(r=.13)$, although participation in social groups is essentially unrelated to age $(r=-.02)$. In contrast, virtual civil society activity is predominately the domain of the young $(r=-.23)$. When age is combined with education, it clearly identifies the core of virtual civil society. Among young, college-educated Americans, 73\% have some Internet interactions, while the comparable percentage among all older Americans (regardless of education level) is $15 \%$ ! The young are the wired generation, who interact through the Internet, IM, text messages and emails-while their parents are attending a church social, a book club, or a pilates class. ${ }^{5}$

\section{The Correlates of Civil Society Activity}

Based on our theoretical expectations for the ways interpersonal social and virtual group activity generate social capital, this section examines their correlates with two areas: citizenship norms and political participation.

\footnotetext{
4 The table presents the count of the number of interactions that were done "often" or "sometimes". The survey skipped these questions for those who did not have access to the Internet at home or at work. They are included in the "none" category in the third column.

5 We use these examples because the most common types of group participation are in a religious group $(16.9 \%)$, cultural or hobby activities $(9.1 \%)$, or a sports club $(8.8 \%)$.
} 
Table 2 Correlations of political norms with interpersonal and virtual civil society activity

Source: CID Survey 2005

Note: Table entries are Pearson $r$ correlations between political norms and indices of interpersonal and virtual civil society participation

* Statistically significant coefficients at the .05 level

\begin{tabular}{|c|c|c|c|}
\hline Social norms & $\begin{array}{l}\text { Social } \\
\text { group } \\
\text { membership }\end{array}$ & $\begin{array}{l}\text { Social } \\
\text { group } \\
\text { participation }\end{array}$ & $\begin{array}{l}\text { Virtual } \\
\text { social } \\
\text { interactions }\end{array}$ \\
\hline Political tolerance & $.17 *$ & $.17 *$ & $.15^{*}$ \\
\hline \multicolumn{4}{|l|}{ Duty-based Citizenship } \\
\hline Vote in elections & $.20 *$ & $.13^{*}$ & $.11^{*}$ \\
\hline Obey law & .00 & -.08 & -.04 \\
\hline Serve on jury & $.10^{*}$ & .04 & .04 \\
\hline Report a crime & $.10^{*}$ & .06 & .04 \\
\hline Serve in military & .02 & -.01 & -.04 \\
\hline $\begin{array}{l}\text { Duty-based } \\
\text { Citizenship Index }\end{array}$ & .03 & -.04 & -.04 \\
\hline \multicolumn{4}{|l|}{ Engaged Citizenship } \\
\hline Form own opinion & $.09 *$ & .05 & $.11^{*}$ \\
\hline $\begin{array}{l}\text { Be active in voluntary } \\
\text { groups }\end{array}$ & $.24 *$ & $.22 *$ & $.17 *$ \\
\hline Be active in politics & $.16^{*}$ & $.18^{*}$ & $.16^{*}$ \\
\hline Help those worse off & $.12^{*}$ & $.09 *$ & $.11^{*}$ \\
\hline $\begin{array}{l}\text { Engaged Citizenship } \\
\text { Index }\end{array}$ & $.23 *$ & $.22 *$ & $.21 *$ \\
\hline
\end{tabular}

\section{Citizenship Norms}

Civil society interactions should socialize participants into the norms of democratic citizenship. This is the essence of the Tocquevillian theme that civil society breeds democratic habits of the heart (Putnam 2000). One key element of a democratic political culture is political tolerance. Interpersonal and virtual activities may bolster political tolerance by connecting participants to a variety of contacts. However, the nature of social interactions - within social groups and within virtual networks-is probably more important than the quantity of such interactions.

The CID assessed political tolerance with an open-ended question framework (Gibson 2008). The survey first asked respondents to identify the group they liked least from a set of critical groups. Then, for their least-liked group, they were asked if this group should be allowed to make a speech in the community, to hold public rallies, or be banned from holding public office. ${ }^{6}$

Political tolerance shares a positive relationship with social group interaction and with virtual social interactions (Table 2). In other words, interactions are important correlates of tolerance regardless of whether these interactions occur face-to-face or in a virtual civil society.

\footnotetext{
6 The three items were answered on a five point agree/disagree scale. The responses to the three items were added together and divided by three to generate a 1-5 scale of tolerance.
} 
Another aspect of citizenship norms flows from Americans' perceptions of what constitutes a "good" democratic citizen and the centrality of participation and social concern to this definition. These norms tap even more directly on the feelings of reciprocity and efficacy that should flow from civil society participation. The CID survey asks respondents a battery of questions on the qualities of good citizenship. Respondents rate the importance for each item. Thus, we measure norms of behavior rather than whether the respondents actually do these things.

In a previous analysis of these items, Dalton (2007, Chap. 2) argued that the items in the CID cluster along two dimensions of citizenship: duty-based and engaged citizenship. We use this framework to organize our presentation. Perceptions of duty-based perceptions include traditional norms, such as the importance of voting in elections, serving on a jury, serving in the military, always obeying the law, and reporting a crime. Engaged citizenship reflects a more participatory, elite-challenging view of citizenship, such as forming one's own opinion, supporting those who are worse off, being active in politics and being active in voluntary groups. We expect that social group and virtual interactions might foster both sets of citizenship norms, but especially engaged citizenship because of its emphasis on collective action and concern for others.

Table 2 displays the relationships of social group and virtual interactions with citizenship norms. Neither social group nor virtual activity is systematically related to the duty-based norms of citizenship displayed in the middle panel of the table. The one exception is voting in elections, which is included on the dutybased dimension of citizenship. In contrast, both interpersonal and virtual interactions are positively related to most examples of engaged citizenship. For example, all three measures have almost identical correlations with a definition of citizenship that involves being active in politics. Again, it appears that the existence of social interaction is more important than the forum in which these interactions occur.

\section{Political Participation}

A long series of analyses predict that participation in social groups bolsters political involvement (Rosenstone and Hansen 1993; Verba et al. 1995; Putnam 2000). Virtual interactions may encourage political involvement through similar mechanisms of stimulation and mobilization. We thus expect a positive relationship of social group and virtual activity with various forms of political participation.

The CID survey is exceptional because it asked about participation in a wide range of political activities (Table 3). In addition to general political interest, the CID asked respondents whether they had participated in 15 different types of political activity over the past year, including voting in the 2004 election. We used a varimax rotated factor analysis to identify four broad dimensions of participation: 
direct action, electoral activity, Internet activity, and protest activity. ${ }^{7}$ The direct action dimension includes boycotting/buycotting, signing a petition, and wearing a campaign or political sticker/button. The electoral/party activity dimension includes working for a candidate, working for a political party, or working for another political organization. The Internet activity dimension includes forwarding an electronic message with political content, participating in politics on the Internet, and visiting the website of a political organization. The protest dimension includes participating in either a legal or illegal protest. We use this framework in presenting results here and in the multivariate analyses below. The indices of each participation mode are factor scores from the factor analysis of items.

Consistent with our expectations, all three measures of social interaction are generally associated with the various forms of political participation. Broad interest in politics (tapped by the frequency of political discussion) shares a strong positive relationship with both social group interaction and virtual social interactions. The index of direct political action in the next panel is also strongly related to social group participation $(r=.37)$ and to virtual social interactions (.23). As we might expect, virtual social interactions are very strongly correlated to various types of Internet-based activity; and there are strong correlations for social group participation. Protest activity is the one area where social interaction is weakly related to political action.

\footnotetext{
7 The survey asked about participation in 15 different forms of political action over the previous 12 months, and whether the respondent voted in the 2004 election. For the full wording of items, see the questionnaire on the project website (note 1). We entered these items into a factor analysis with varimax rotation. Four dimensions had eigenvalues greater than 1.0, and were used to create factor scores for the analyses in Table 4 . The factor loadings are:
}

\begin{tabular}{llllr}
\hline & Direct & Electoral & Internet & Protest \\
\hline Signed petition & .72 & .16 & .12 & .02 \\
Boycotted products & .72 & .07 & .19 & .27 \\
Bought items for ethical reasons & .66 & .04 & .24 & .26 \\
Worn sticker/badge & .60 & .38 & .22 & -.13 \\
Donated money & .51 & .44 & .02 & .03 \\
Worked for political party & .12 & .81 & .13 & .19 \\
Worked for candidate campaign & .12 & .80 & .09 & .05 \\
Worked for political organization & .08 & .62 & .24 & .36 \\
Forward email political content & .18 & .13 & .82 & -.04 \\
Internet political activity & .09 & .22 & .79 & .13 \\
Visit website political & .40 & .09 & .68 & .08 \\
Illegal protest & .04 & .16 & .09 & .71 \\
Lawful demonstration & .31 & .10 & .03 & .66 \\
Vote & .27 & .31 & .12 & -.32 \\
Contacted a politician & .39 & .49 & .18 & -.07. \\
\hline
\end{tabular}


Table 3 Correlations of political participation with interpersonal and virtual civil society activity

\begin{tabular}{|c|c|c|c|}
\hline Political involvement & $\begin{array}{l}\text { Social } \\
\text { group } \\
\text { membership }\end{array}$ & $\begin{array}{l}\text { Social } \\
\text { group } \\
\text { participation }\end{array}$ & $\begin{array}{l}\text { Virtual } \\
\text { social } \\
\text { interactions }\end{array}$ \\
\hline Political discussion & $.28 *$ & $.19^{*}$ & $.23^{*}$ \\
\hline Signed a petition & $.33 *$ & $.30 *$ & $.27 *$ \\
\hline Boycotting a product & $.26^{*}$ & $.29 *$ & $.20 *$ \\
\hline $\begin{array}{l}\text { Bought a product for } \\
\text { ethical, political reasons }\end{array}$ & $.27 *$ & $.31 *$ & $.24 *$ \\
\hline $\begin{array}{l}\text { Display political } \\
\text { sticker/banner }\end{array}$ & $.33 *$ & $.32 *$ & $.22 *$ \\
\hline Donate money & $.33 *$ & $.24^{*}$ & $.18^{*}$ \\
\hline Direct action index & $.36 *$ & $.37 *$ & $.23^{*}$ \\
\hline $\begin{array}{l}\text { Work for a political } \\
\text { party or action group }\end{array}$ & $.27 *$ & $.19^{*}$ & $.19^{*}$ \\
\hline $\begin{array}{l}\text { Worked for a political } \\
\text { campaign }\end{array}$ & $.23 *$ & $.15^{*}$ & $.17^{*}$ \\
\hline $\begin{array}{l}\text { Work for other political } \\
\text { group }\end{array}$ & $.24 *$ & $.20 *$ & $.21 *$ \\
\hline $\begin{array}{l}\text { Electoral participation } \\
\text { index }\end{array}$ & $.26^{*}$ & $.15^{*}$ & $.14^{*}$ \\
\hline $\begin{array}{l}\text { Forward electronic } \\
\text { message with political } \\
\text { content }\end{array}$ & $.27 *$ & $.18^{*}$ & $.29 *$ \\
\hline $\begin{array}{l}\text { Participated in Internet } \\
\text { political activities }\end{array}$ & $.16^{*}$ & $.22 *$ & $.29 *$ \\
\hline $\begin{array}{l}\text { Visit website political } \\
\text { organization }\end{array}$ & $.31 *$ & $.32 *$ & $.35^{*}$ \\
\hline $\begin{array}{l}\text { Internet participation } \\
\text { index }\end{array}$ & $.18 *$ & $.16^{*}$ & $.30 *$ \\
\hline Illegal demonstration & .04 & .04 & .01 \\
\hline Lawful demonstration & .05 & $.19 *$ & $.16^{*}$ \\
\hline Protest participation index & -.07 & .06 & .04 \\
\hline Contact a politician & $.30 *$ & $.21^{*}$ & $.21^{*}$ \\
\hline Vote & $.24 *$ & $.18^{*}$ & $.12^{*}$ \\
\hline
\end{tabular}

Source: CID Survey 2005

Note: Table entries are pearson $r$ correlations between political participation and indices of interpersonal and virtual civil society participation

* Statistically significant coefficients at the .05 level

Across most political activities, social group membership has a stronger relationship than group participation-countering the interpersonal interaction claims of social capital theory. This suggests that group membership may be less of a causal factor in stimulating participation than a spurious correlate of action. Those who are more likely to be engaged will join organizations, even if they do not participate in these groups.

In summary, political activity displays similar correlations with social group participation and virtual interactions. This reaffirms the point that virtual interaction can stimulate the positive aspects of democratic social capital as found in traditional social group interactions. 


\section{Multivariate Analyses}

As a final step in our research, we developed multivariate analyses to ensure that the social capital relationships we described are not spurious correlations due to other factors. For instance, more highly educated and younger individuals are more likely to have online skills (Best and Krueger 2005; Pew 2010). Further, relationships between the Internet and social capital may influenced by the fact that more highly educated individuals are more likely to have social group connections in the first place (Nie 2001).

We entered both interpersonal social group participation and virtual social activity into multiple regressions predicting the indices developed in the previous analyses. We use group participation rather than simple group membership, because it is supposed through interpersonal interactions that social groups stimulate social capital. These regressions include other potential influences on these dependent variables, such as age, education, gender, race, ethnicity, and liberal/conservative orientations. We do not specify the theoretical logic of each of these control variables for each of the models. However, we selected these variables because they routinely are linked to several of these dependent variables. For instance, education and age are common predictors of political tolerance and participation, while also displaying significant correlations with both group and virtual social interaction.

To an extent, these models 'overcontrol' for civil society effects because we look at the impact of each index of activity while controlling for the other-since these two forms of activity are positively related, we are trying to isolate their independent effects. If either social activity variable alone is included in these models, the effects of each typically are significantly stronger.

Our findings are presented in Table 4. The first columns present citizenship norms. Although both variables are significantly related to tolerance in simple bivariate relationships, the impact of interpersonal social group and virtual activity substantially overlaps with other variables in the model-and each othermoderating the impact of each variable in the regression analysis. The next two columns display the models for duty-based and engaged norms of citizenship. Neither social group nor virtual interaction reaches statistical significance for dutybased citizenship, consistent with Table 2. These traditional norms of social order (and the norm to vote) do not seem to be conditioned by civil society engagement. In contrast, both social group and virtual interaction are significant predictors of engaged citizenship norms. Virtual social activity is essentially as conducive as participation in social groups in building more grassroots, directly engaged values of citizenship that are the habits of the heart that Tocqueville stressed.

The last five columns in the table predict different aspects of political participation. We use political discussion as a general measure of political interest; virtual social interaction is an even stronger predictor of political discussion than in-person social group participation, and both are statistically significant. Similarly, both forms of interaction are positive indicators of direct action and electoral activity even while controlling for the other variables in this model. As we should expect, virtual interaction is much more strongly related to Internet-based political activity. Virtual interaction is not related to protest activity in this multivariate 


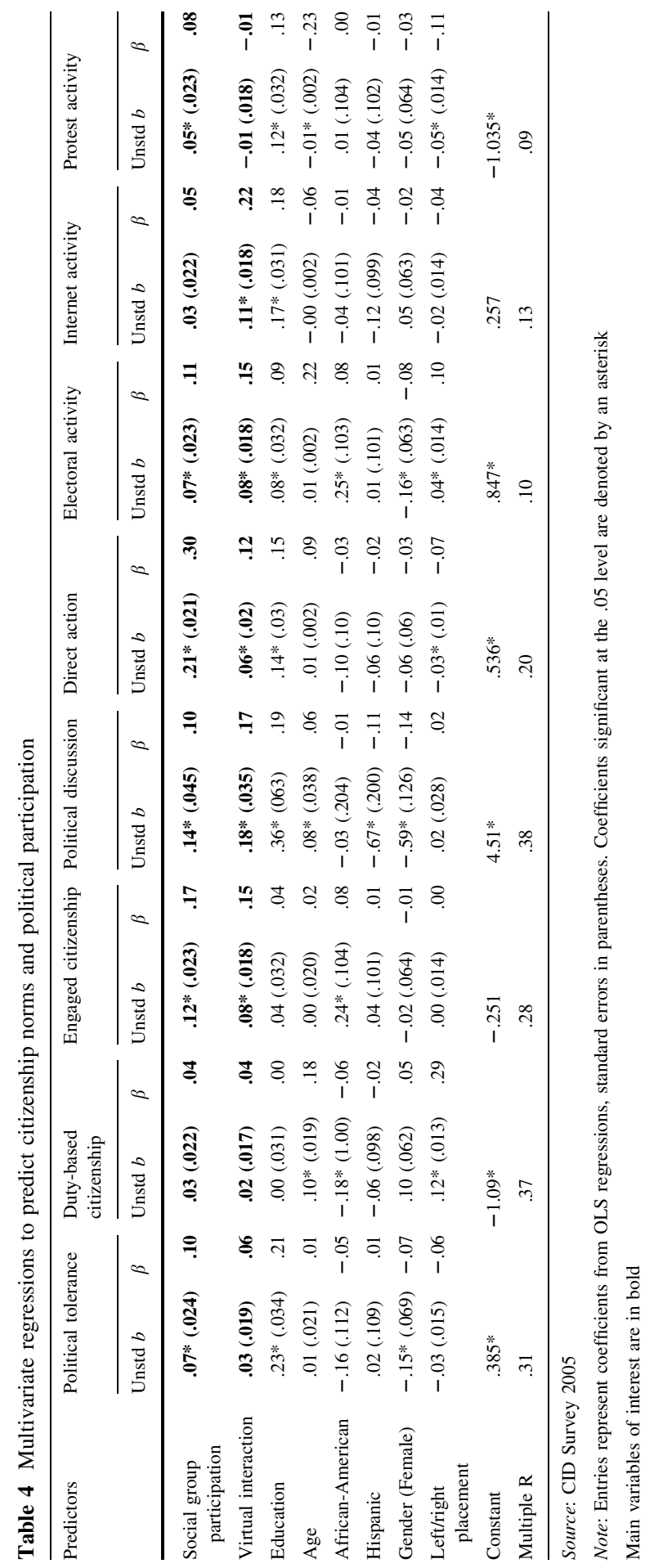


analysis. The geographically disperse nature of the Internet may sever the link between virtual interactions and protest. It is likely to be more difficult to mobilize a distant friend met on the Internet to participate in a local protest.

In short, interpersonal and virtual interactions are both independently linked to political participation, even after controlling for demographic and ideological influences. ${ }^{8}$ Social interactions outside of politics increase the odds that people will become involved in politics. The independent effects of virtual social interactions on tolerance are more ambiguous, but that might be because of the overlap with traditional group forms of social action that are also controlled in the model. For instance, in a model predicting political tolerance with only virtual social interaction (excluding social groups), virtual interactions have a significant positive effect $(\beta=.08)$. Trying to isolate the overlapping effects of social group and virtual interaction may overcontrol for the effects of each.

\section{Conclusions}

Many leading scholars have recently lamented the decline of civic engagement and social capital in America, claiming that too many of us are sitting at home in front of our televisions sets, and more recently our computer monitors, and not personally connecting to our fellow citizens (Putnam 2000; Macedo et al. 2005; National Conference on Citizenship 2006). Initially these criticisms might have been correct. Studies of traditional social group activity argued that face-to-face interaction in social groups was necessary to generate positive social capital (Putnam 2000; Warren 2000). Early Internet usage also offered only a one-directional flow of information with minimal interaction with other people. Moreover, previous studies of Internet users yielded mixed results on the potential social capital benefits of this new medium.

The nature of Internet interaction has changed dramatically, however, with new innovations such as social networking sites, blogs and sites such as MeetUp.org. Rather than study simple Internet usage as many previous studies have done, we examined the amount of social interaction that individuals pursue through the Internet. This, we believe, provides a closer test of the theorized impact of social interactions in the sense that our virtual interaction measure, similar to participation in traditional social groups, captures people interacting with other people, as opposed to more passive forms of Internet activity.

Our findings suggest that the mechanisms through which citizens interact with others are evolving with the new technology of the Internet (and other new technologies). Indeed, more people are looking at their computer monitors or smartphone screens, and many use this experience to connect to others in their social groups, others who share their cultural, social or political interests, and to

\footnotetext{
${ }^{8}$ Alternative specifications of these models that include control variables such as political interest and strength of party identification yield substantially similar results. We present the most basic models and focus on the impact our variables of interest, interpersonal social group participation and virtual interactions. In addition, the unstandardized $\mathrm{b}$ values generally paint the same picture as the betas, minimizing the potential for skewed distributions affecting the results.
} 
garner information about the world and their fellow citizens through this new medium.

Even if Facebook cannot completely substitute for bowling leagues and choral societies, virtual civil society appears to have many of the same benefits for citizen norms and political involvement as traditional civil society. We find that virtual activity is most clearly linked to a participatory style of citizenship, first through the participatory norms of engaged citizenship. Second, virtual activity is positively associated with several forms of political engagement. Moreover, these participatory benefits persist even in multivariate analyses controlling for social group interactions and a set of potential demographic predictors.

Not only is virtual civil society expanding, but so is virtual political activity (Mossberger et al. 2008; Schlozman et al. 2009). The majority of messages that members of Congress receive from their constituents now come in the form of email. The 2008 Obama campaign demonstrated how Internet-based fundraising and voter mobilization can transform the nature of presidential elections. The expansion of e-government activities provides further political access for the computer literate. Thus, as these Internet-based forms of political activity grow, they further enable the potential of Internet-based social networks to become politically engaged.

Having demonstrated these broad patterns, they should encourage more focused analyses on the varieties of virtual social activity, paralleling previous research on the varieties of social group membership. For instance, we expect that interactions based on existing social networks, as represented in some of our interaction items, would deepen bonding relationships. ${ }^{9}$ In contrast, virtual activity that expands beyond immediate personal networks, such as interactions with people from different countries or interactions with strangers, may generate more bridging relationships. Facebook exchanges with coworkers may add less to existing stocks of social capital than meeting new fellow hobbists or political activists in another city. The Internet seems especially capable of creating new networks unrestrained by geographic proximity, and renewing connections with friends at long distance. Such 'weak ties' are often stressed as the most valuable aspect of social networks (Granovetter 1973). There is also anecdotal evidence that multi-person online gaming may also have the same social capital potential as bowling leagues. With the growth of Internet activity, our research focus should examine these more detailed questions of social capital formation.

In addition, our results raise some new questions about the impact of traditional group membership. In most relationships a simple count of the number of group membership displays a stronger correlation than a measure of participation in these groups. The logic of civil society theory would suggest that participation should be more important than simple membership, because it is through interpersonal interactions that social capital supposedly develops. Similar to our findings, researchers find comparable differences between passive and active social group membership in explaining social trust and political participation across a set of

\footnotetext{
${ }^{9}$ For instance, the 2007 Australian Election Study replicated the virtual social capital questions, and researchers have begun to examine the relationships between different types of on-line interaction and indices of bridging and bonding social trust (Gibson and McAllister 2009).
} 
European democracies (Wollebak and Selle 2007; van der Meer and van Ingen 2009). These patterns suggest that part of the correlation between group membership and social capital does not reflect the socialization experience of interpersonal interaction, but the selection process by which individuals join social groups. Thus, past civil society research based on group membership statistics may overestimate the social learning impact of civil society on the norms and behaviors linked to social capital.

In summary, our findings suggest that social capital can be generated in multiple ways, and those mechanisms are changing with social, economic and technological changes in America. Specifically, virtual civil society has the potential to be an important new source of social capital formation in the contemporary age. Given the substantial group in Internet social interaction since our 2005 survey (Pew 2010), and the substantial potential for further growth, the current aggregate social capital benefits are undoubtedly greater than those presented here.

Open Access This article is distributed under the terms of the Creative Commons Attribution Noncommercial License which permits any noncommercial use, distribution, and reproduction in any medium, provided the original author(s) and source are credited.

\section{References}

Baumgartner, J. C., \& Morris, J. S. (2009). MyFaceTube politics: Social networking web sites and political engagement of young adults. Social Science Computer Review, 25(3), 319-338.

Bender, T. (1978). Community and social change in America. New Brunswick, NJ: Rutgers University Press.

Best, S. J., \& Krueger, B. S. (2005). Analyzing the representativeness of Internet political participation. Political Behavior, 27(2), 183-216.

Boulianne, S. (2009). Does Internet use affect engagement? A meta-analysis of research. Political Communication, 26, 193-211.

Corrado, A., \& Firestone, C. M. (1996). Elections in cyberspace: Toward a new era in American politics. Washington DC: Aspen Institute.

Dalton, R. (2007). The good citizen: How the young are reshaping American politics. Washington, DC: Congressional Quarterly Press.

Ellison, N. B., Steinfield, C., \& Lampe, C. (2007). The benefits of Facebook "friends": Social capital and college students' use of online social network sites. Journal of Computer-Mediated Communication, $12,1143-1168$.

Gibson, J. (2008). Intolerance and political repression in the United States: A half century after McCarthyism. American Journal of Political Science, 52(1), 96-108.

Gibson, R. K., \& McAllister, I. (2009). Revitalising participatory politics? The internet, social capital and political action. Paper presented at the Annual Meetings of the American Political Science Association. Toronto, Canada.

Granovetter, M. (1973). The strength of weak ties. American Journal of Sociology, 78(6), 1360-1380.

Hall, P. D. (1999). Vital signs: Organizational population trends and civic engagement in New Haven, Connecticut. In T. Skocpol \& M. Fiorina (Eds.), Civic engagement and American democracy. Washington DC: Brookings Institution.

Ho, S. S., \& McLeod, D. M. (2008). Social-psychological influences on opinion expression in face-toface and computer-mediated communication. Communication Research, 35(2), 190-207.

Hooghe, M., \& Stolle, D. (Eds.) (2003). Generating social capital: The role of voluntary associations, institutions and government policy. New York: Palgrave/Macmillan.

Howard, M. M., \& Gilbert, L. (2008). A cross-national comparison of the internal effects of participation in voluntary organizations. Political Studies, 56, 12-32. 
Jennings, M. K., \& Zeitner, V. (2003). Internet use and civic engagement: A longitudinal analysis. Public Opinion Quarterly, 67, 311-334.

Johnson, T., \& Kaye, B. (2003). A boost or bust for democracy? How the web influences political attitudes and behaviors in the 1996 and 2000 presidential elections. Press/Politics, 8, 9-34.

Kraut, R., et al. (1998). Internet paradox: A social technology that reduces social involvement and psychological well-being? American Psychologist, 53(9), 1017-1032.

Kraut, R., et al. (2002). Internet paradox revisited. Journal of Social Issues, 58(1), 49-74.

Krueger, B. S. (2002). Assessing the potential of Internet political participation in the United States: A resource approach. American Politics Research, 30(5), 476-498.

Ladd, E. C. (1996). The data just don't show erosion of America's social capital. Public Perspectives, 7(4), 5-22.

Macedo, S., et al. (2005). Democracy at risk: How political choices undermine citizen participation, and what we can do about it. Washington, DC: Brookings Institution Press.

McKenna, K. Y. A., \& Bargh, J. A. (2000). Plan 9 from cyberspace: The implications of the Internet for personality and social psychology. Personality and Social Psychology Review, 4(1), 57-75.

Mossberger, K., Tolbert, C. J., \& McNeal, R. S. (2008). Digital citizenship: The Internet, society and participation. Cambridge, Mass.: MIT Press.

National Conference on Citizenship. (2006). America's civic health index: Broken engagement. Washington, DC: National Conference on Citizenship.

Nie, N. H. (2001). Sociability, interpersonal relations and the Internet: Reconciling conflicting findings. American Behavioral Scientist, 45, 420-435.

Nie, N. H., \& Erbring, L. (2002). Internet and society: A preliminary report. IT \& Society, 1(1), $275-283$.

Norris, P. (2002). The bridging and bonding role of online communities. International Journal of Press/ Politics, 7(3), 3-13.

Pew. (2010). Pew Internet and American life project. www.pewinternet.org/trends.asp.

Putnam, R. (1993). Making democracy work. Princeton: Princeton University Press.

Putnam, R. (2000). Bowling alone: The collapse and renewal of American community. New York: Simon \& Schuster.

Putnam, R. (Ed.). (2002). Democracies in flux: The evolution of social capital in contemporary society. Oxford: Oxford University Press.

Putnam, R., Feldstein, L. M., \& Cohen, D. (2003). Better together: restoring the American community. New York: Simon \& Schuster.

Rosenstone, S., \& Hansen, M. (1993). Mobilization, participation, and democracy in America. New York: Macmillian Publishing Company.

Scheufele, D., \& Nisbet, M. (2002). Being a citizen online: New opportunities and dead ends. Press/Politics, 7, 55-75.

Schlozman, K. L., Verba, S., \& Brady, H. E. (2009). The weapon of the strong? Participatory inequality and the Internet. Paper presented at the Annual Meeting of the Midwest Political Science Association. Chicago, IL.

Shah, D., et al. (2002). Nonrecursive models of internet use and community engagement questioning whether time spent online erodes social capital. Journalism \& Mass Communication Quarterly, 79, 964-987.

Sirianni, C., \& Friedland, L. (2001). Civic innovation in America: Community empowerment, public policy and the movement for civic renewal. Berkeley, CA: University of California Press.

Skocpol, T., \& Fiorina, M. P. (Eds.). (1999). Civic engagement in American democracy. Washington, DC: Brookings Institution Press.

Stolle, D., \& Hooghe, M. (2005). Inaccurate, exceptional, one-sided or irrelevant? The debate about the alleged decline of social capital and civic engagement in Western societies. British Journal of Political Science, 34(4), 703-721.

Stolle, D., \& Rochon, T. (1998). Are all associations alike? Member diversity, associational type and the creation of social capital. American Behavioral Scientist, 42(1), 47-65.

Uslaner, E. (1998). Democracy and social capital. In M. E. Warren (Ed.), Democracy and trust. Cambridge: Cambridge University Press.

Valenzuela, S., Park, N., \& Kee, K. F. (2009). Is there social capital in a social network site? Facebook use and college students' life satisfaction, trust and participation. Journal of Computer-Mediated Communication, 14, 875-901. 
van der Meer, T., \& van Ingen, E. (2009). Schools of democracy? Distentangling the relationship between civic participation and political action in 17 European countries. European Journal of Political Research, 48, 281-308.

Verba, S., Schlozman, K. L., \& Brady, H. E. (1995). Voice and equality: Civic voluntarism in American politics. Cambridge: Harvard University Press.

Warren, M. (2000). Democracy and association. Princeton: Princeton University Press.

Wellman, B., et al. (2001). Does the Internet increase, decrease or supplement social capital? Social networks, participation and community involvement. American Behavioral Scientist, 45, 436-455.

Wollebak, D., \& Selle, P. (2007). Origins of social capital: Socialization and institutionalization approaches compared. Journal of Civil Society, 3, 1-24.

Wuthnow, R. (1998). Loose connections. Cambridge: Harvard University Press. 